\title{
CHRONIC CARDITIS IN A CHILD OF NINETEEN MONTHS
}

\author{
BY \\ B. E. McCONNELL, M.D., M.R.C.P. \\ From the Department of Pathology, Bristol University
}

(Received for Publication, June 22, 1949)

Chronic carditis in infancy is so rare that the following case, which presented both clinical and pathological problems, is considered worth reporting.

\section{Case History}

A.N., a boy and the only child, was stated to have been a fortnight premature and to have weighed $5 \frac{1}{2} \mathrm{lb}$. at birth. Breast fed for one month, he was then given bottle feeds as his mother had insufficient milk. On this he thrived, and subsequent progress was normal with no history of any illness until his last. At 16 months he weighed $21 \mathrm{lb}$., and at 18 months he had 12 teeth and could walk and speak a few words. Both parents were healthy, and there was no history of illness during the mother's pregnancy.

Three weeks before admission, at the age of 19 months, the child became fractious and appeared unwell. The only abnormal physical sign was stiff and painful middle fingers, but the general condition deteriorated and he was eventually sent to hospital.

Clinical Examination. On admission the child was lying quietly, but resented disturbances. The cheeks and mucous membranes were pale, the limbs hypotonic, and the nails spoon-shaped. There was sweating and apparent recent loss of weight, the actual weight being $18 \mathrm{lb}$. $3 \mathrm{oz}$. The skull circumference was $19 \frac{1}{2}$ in. (normal average at this age, 18 in.), and the anterior fontanelle admitted a finger tip, indicating delay in closing, which is normally complete at 18 months. The middle finger of each hand was semi-flexed and painful and slight oedema of the feet and lumbar region was noticed.

The temperature was $99^{\circ} \mathrm{F}$., respiration 40 , and pulse 135 per minute. The blood pressure was $75 / 40$. Scattered râles were noted.

The apex beat was not localized on palpation, but on percussion the area of cardiac dullness extended three finger breadths to the left of the sternum in the fourth intercostal space and one finger breadth to the right in the third space. On auscultation a blowing apical systolic murmur, conducted into the axilla, was heard. A systolic murmur was also audible to the right of the sternum.

The liver was palpable two finger breadths below the costal margin and the spleen one finger breadth.

Special Investigations. Radiographs showed an enlarged heart and some opacity of the left upper and lower zones in the chest. The fingers appeared normal.

The Mantoux reaction $(1: 10,000)$ and the tuberculin patch and jelly tests were negative.

BLOOD EXAMINATION. R.B.C. $4,200,000 / \mathrm{cu}$. mm.; $\mathrm{Hb} 72 \%$ (Haldane). The film showed mild anisocytosis and slight hypochromia. W.B.C. 12,200 (neutrophils, $52 \%$; eosinophils, $1 \%$; lymphocytes, $42 \%$; monocytes, $5 \%$ ).

Progress. For the first three days after admission there was little change in the child's condition, but the fourth day brought the onset of marked dyspnoea and cyanosis. An oxygen tent gave slight relief of symptoms, but penicillin and sulphathiazole in ordinary doses were without effect, and the clinical course was rapidly downhill with increasing dyspnoea, cyanosis, and sweating. Death occurred on the ninth day with great respiratory distress.

No clinical diagnosis had been made. The possibility of rickets, tuberculosis, or a pyogenic infection had been dismissed after the special investigations.

\section{Post-mortem Findings}

Necropsy was performed $9 \frac{1}{2}$ hours after death.

The body showed little subcutaneous fat. Each pleural cavity contained about $100 \mathrm{ml}$. of strawcoloured fluid with no clot. The pericardium appeared normal.

The heart (Fig. 1) weighed $65 \mathrm{~g}$. (normal at this age is 52 g.). On section the right ventricle measured $4.5 \mathrm{~mm}$. in thickness and the left ventricle $11 \mathrm{~mm}$. The striking feature was the great thickening of the endocardium. Both mitral and tricuspid valves felt like cartilage, and the chordae were short, thick and fused. At the bases of these valves fibrosis could be seen extending into the 
myocardium, and in other areas of the muscle small patches of fibrosis were evident, particularly at the bases of the papillary muscles.

The contiguous margins of the cusps of the aortic valve were fused, while the free margins were thick and hard. The adjacent aortic wall was also thickened, and at a distance of $2 \mathrm{~cm}$. above the valve measured approximately $2 \mathrm{~mm}$. in thickness. Above the valve the lumen of the aorta appeared normal throughout, while the intimal surface was quite smooth.

Both lungs showed marked chronic venous congestion. The costo-chondral junctions and middle fingers were normal on section and no abnormality was found in any other organ or tissue.

Histology. Sections were taken from both right and left sides of the heart to show the auriculo-ventricular junction and the attachment and cusp of the appropriate valve. The section from the left side included the circumflex branch of the left coronary artery. The histological picture in each section was similar. The epicardium appeared normal. The myocardium showed areas of fibrosis adjacent to the blood vessels. There was also marked fibrosis at the base of the valve, the fibrous tissue interlacing with the muscle at this point. The circumflex branch of the left coronary artery showed subintimal fibrosis, very marked replacement fibrosis of its medial coat, and also paravascular fibrosis. The valves were both thick and consisted of hyaline fibrous tissue. No vegetation and no signs of acute or subacute inflammation were evident.

The intima of the aorta was normal (Fig. 2). The media was normal at its inner part, but near the adventitial junction had been involved in a severe inflammatory process. Fibrosis was marked adjacent to the vasa vasorum and in many places islets of elastic tissue were surrounded by fibrous tissue, as if cut off by an advancing tide. The adventitia was irregularly thickened and consisted of hyaline scar tissue.

\section{Discussion}

The problem here was to ascertain the nature and age of the lesion, which for practical purposes was confined to the heart and aorta. The picture of myocardial fibrosis, valvular distortion and thickening with fusion of chordae tendineae, is so highly suggestive of a chronic rheumatic process that it is hard to see what alternative diagnosis could be made. The only logical possibility is an endocarditis, not rheumatic, of unknown aetiology, and as yet not clearly defined. Verrucose endocarditis due to disseminated lupus erythematosis does not meet the case as no abnormality was found in any other organ, nor did the clinical picture in any way suggest the disease. Fiedler's myocarditis spares the endocardium, which in this case was the most heavily damaged part. So-called idiopathic cardiac hypertrophy is an improperly understood condition. The literature on the subject was reviewed by Kugel and Stoloff in 1932 and again by Kugel in 1939. While the clinical picture they describe is similar to that in this case, the endocardium is only slightly, if at all, involved. Moreover, a congenital lesion cannot be considered as the picture is so obviously that of a chronic healed inflammatory process.

If rheumatic carditis is to be considered, then an acute rheumatic process is implied, which is very rare in infants.

Paul White (1944) states that 'rheumatic heart disease . . . is especially -rare before the age of two years '. Various writers have described the disease however. In 1896 Abrahams reported six cases in new-born infants whose mothers were suffering from rheumatic fever while in labour. The infants all had arthritic signs or cardiac murmurs, the 
signs and symptoms responding to salicylates (but no follow-up of the patients is reported). Cathala and others (1936) described a child of 22 months with limb pains, an apical systolic murmur, and enlargement of the heart. The symptoms responded to salicylates, but the murmur remained and was considered to indicate mitral incompetence. Saubidet (1936) described three infants of 8,18 , and 21 months who showed joint pains and fever, but no abnormal cardiac signs; the symp. toms responded to salicylates. These cases cannot be regarded as proven, although Cathala's patient showed a clinical course strongly resembling that of rheumatic carditis. Denzer, however (1924), reported three cases of infants under two years in which the diagnosis of rheumatic carditis was proven at necropsy. Two of these cases were acute, while the third was estimated at six months' duration.

Kissane and Koons (1933) described a case in which a woman was ill during pregnancy with rheumatic fever. The child was born with arthritis and cardiac murmursand remained under the observation of the one physician until he was nine years old when he died in an attack of acute rheumatic fever. Necropsy showed chronic rheumatic carditis with a recent acute exacerbation.

Fischer (1934) described an infant one year of age dying with pneumonia. A clinical diagnosis of congenital heart disease was disproved at necropsy when rheumatic carditis, affecting mainly the mitral valve, was found.

McIntosh and Wood (1935) reviewed 24 cases in infants or young children in the New York Babies' Hospital. In six of these the diagnosis was confirmed at necropsy, the youngest child being 20 months old at death and suffering from acute rheumatism at the time.

There is, therefore, sufficient precedent to consider a diagnosis of rheumatic carditis in a child of 19 months. Having made this decision the next problem is to attempt to assess the age of the lesion. The recent work of McKeown (1945) on the evolution of the Aschoff nodule has shown that healing takes some nine months and that before this the lesions have a characteristic architecture and can be recognized as specific entities. When healing is complete there is simply scar tissue with no specific a rchitecture, although the paravascular and subendocardial distribution is highly suggestive, as it was in this case. On these grounds it is suggested that this child had acute rheumatism early in its first year of life.

\section{Summary}

A case is reported of a child dying at the age of 19 months in which necropsy revealed a cardiac lesion suggestive of chronic rheumatic carditis.

I wish to express my thanks to Dr. Beryl Corner, under whose care this child was at the Bristol Children's 
Hospital; also to Professors T. F. Hewer and C. Bruce Perry for helpful criticism and advice. My thanks are also due to Mr. G. W. Griffin and Mr. G. Rogers of the Department of Pathology, Bristol University, for the histology and photographs.

\section{REFERENCES}

Abrahams, R. (1896). Med. Rec., N.Y., 50, 547.

Cathala, J., Sustendal, J., and Patey, G. (1936). Bull. Soc. Pédiat., Paris, 34, 187.

Denzer, B. S. (1924). J. Amer. med. Ass., 82, 1243.
Fischer, V. E. (1934). Amer. J. Dis. Child., 48, 590.

Kissane, R. W., and Koons, R. A. (1933). Arch. intern. Med., 52, 905.

Kugel, M. A., and Stoloff, E. G. (1932). Amer. J. Dis. Child., 45, 828.

Kugel, M. A. (1939). Amer. Heart J., 17, 602.

McIntosh, R., and Wood, C. L. (1935). Amer. J. Dis. Child., 49, 844.

McKeown, F. (1945). Ulster med. J., 14, 97.

Saubidet, E. (1936). Sem. méd., 2, 1077.

White, P. (1944). 'Heart Disease,' 3rd Ed., 327. Macmillan. New York. 